\title{
Sarcoplasmic/Endoplasmic Reticulum Calcium ATPase 2
}

National Cancer Institute

\section{Source}

National Cancer Institute. Sarcoplasmic/Endoplasmic Reticulum Calcium ATPase 2. NCI

Thesaurus. Code C106418.

Sarcoplasmic/endoplasmic reticulum calcium ATPase 2 (1042 aa, 115 kDa) is encoded by the human AT P2A2 gene. This protein plays a role in both heart contraction and ATP hydrolysis. 